\title{
A Case of Neonatal Hypocalcaemia Due to Maternal Vitamin D Deficiency
}

\author{
AYESHA HASINA ${ }^{1}$, M QUAMRUL HASSAN ${ }^{2}$
}

\section{Introduction}

Neonatal hypocalcaemia $(\mathrm{NH})$ is a commonly reported metabolic abnormality in neonate. Ionized calcium is vital for various metabolic pathways like blood coagulation, neuronal depolarization, integrity of cell membrane, enzyme catalysis etc. Major part of the body calcium exists in bones and muscles (99\%) and the rest of the calcium is present in extracellular fluid (1\%). In extracellular fluid about $40 \%$ calcium is bound to albumin, another $10 \%$ is bound to citrate, phosphorus, lactate and sulfate and the rest $(50 \%)$ exists as ionized free form, help in metabolic functions. ${ }^{1,2}$ Hypocalcaemia has significant negative impact on newborn health. It is defined as total serum calcium of $<8 \mathrm{mg} / \mathrm{dL}(2 \mathrm{mmol} / \mathrm{L})$ or ionized calcium of $<1.2 \mathrm{mmol} / \mathrm{L}$ in term neonates, and $<7 \mathrm{mg} / \mathrm{dL}(1.75$ $\mathrm{mmol} / \mathrm{L}$ ) of total calcium or $<4 \mathrm{mg} / \mathrm{dL}(1 \mathrm{mmol} / \mathrm{L})$ of ionized calcium in preterm infants. ${ }^{3}$ Causes of neonatal hypocalcaemia is diverse like prematurity, perinatal asphyxia, cow milk feeding. Maternal Vitamin $D$ deficiency has also been reported as a cause of neonatal hypocalcaemia. We are reporting a case of neonatal hypocalcaemia attributed to maternal Vitamin $\mathrm{D}$ deficiency in Asian context.

\section{Case Report}

9 days old out born boy was admitted in NICU of Apollo Hospitals Dhaka on $3^{\text {rd }}$ September 2014 with h/o seizures. In immediate neonatal period, in a different hospital where he was born, the baby developed mild transient tachypnoea of newborn which required no active management. He was discharged from that hospital on $3^{\text {rd }}$ postnatal day. At $7^{\text {th }}$ day of age he developed convulsion and was re-admitted to that hospital. His convulsion was generalized in nature, 45 episodes with duration of approximately 10 seconds each. He was initially treated in that hospital with anticonvulsant, antibiotic and calcium gluconate but as condition was deteriorating, he was transferred to Apollo hospital at $9^{\text {th }}$ day of age.

1. Registrar, Neonatology, Apollo Hospitals Dhaka.

2. Senior Consultant, Pediatrics and Neonatology, Apollo Hospitals Dhaka.

Correspondence: Dr. Ayesha Hasina.
The pregnancy was unremarkable and the baby was born at term by an uncomplicated caesarian section. His birth weight was 2580 gram (10th to 25th percentile). Mother had bronchial asthma, otherwise family history was noncontributory. There was no history of fever, trauma or sepsis related risk factors. The baby was breastfed and supplemented with formula feed.

The baby's weight was 2580gram. He was afebrile with normal vital signs. He had no dysmorphic features and physical examination was otherwise unremarkable. Twenty four hours after admission, the baby developed 2 episodes of focal convulsion for 10 seconds each.

Initial blood work showed normal septic screening, renal function and electrolytes with hypocalcemia (total calcium $6 \mathrm{mg} / \mathrm{dl}$ (8.5 to $10.5 \mathrm{mg} / \mathrm{dl}$ ) and hyperphosphataemia. Blood glucose level was $4.3 \mathrm{mmol} / \mathrm{L}$. The diagnosis was revealed after further maternal history and blood tests. On further query, the mother did not take any antenatal vitamin supplements. The baby had not been started on vitamin $\mathrm{D}$ supplements.

Vitamin $D$ deficiency in the infant was diagnosed on the basis of a low 25-hydroxy vitamin D level at 19 $\mathrm{nmol} / \mathrm{L} \quad(<25$ deficient , $75-250$ sufficient $)$. The neonate's parathyroid hormone (PTH) level was at upper normal range at $68 \mathrm{pg} / \mathrm{ml}$ (normal 12 to $72 \mathrm{pg} /$ $\mathrm{ml})$. Cranial ultrasound was completely normal.

Investigations of the baby's mother demonstrated 25hydroxy vitamin D level of $20 \mathrm{nmol} / \mathrm{L}$ (normal $75 \mathrm{nmol} /$ $\mathrm{L}$ to $250 \mathrm{nmol} / \mathrm{L}$ ) and an elevated PTH level of $88 \mathrm{ng} / \mathrm{L}$ (normal $10 \mathrm{ng} / \mathrm{L}$ to $65 \mathrm{ng} / \mathrm{L}$ ), confirming the diagnosis of vitamin $D$ deficiency in the mother.

The baby was managed with an intravenous calcium gluconate infusion followed by oral calcium, vitamin D3 drop. S. calcium became normal after 7 days of treatment and the seizures resolved within $48 \mathrm{~h}$ of admission. The results of a full septic workup were negative. Baby was discharged at $15^{\text {th }}$ postnatal day with S.calcium level at $8.1 \mathrm{mg} / \mathrm{dl}$.The baby was advised to continue with oral vitamin $\mathrm{D}$ and calcium 
gluconate After discharge baby was followed up in outpatient up to 15 months of age. No further convulsion had occurred and $\mathrm{S}$. calcium returned to normal ( $\mathrm{S}$ calcium $10 \mathrm{mg} / \mathrm{dl}$ at $29^{\text {th }}$ days age ). At $15^{\text {th }}$ months of age, his weight was $9 \mathrm{~kg}$ and height $76 \mathrm{~cm}$ (in between $10^{\text {th }}$ to 25 th centile ). $X$ ray knee joint revealed no evidence of rickets.

\section{Discussion}

Neonatal hypocalcaemia $(\mathrm{NH})$ is a common metabolic event in the neonatal period. $\mathrm{NH}$ is classified into earlyand late- based on the time of presentation. ${ }^{1}$ The early $\mathrm{NH}$ usually manifests within 72 hours after birth, requiring short term calcium supplementation, and it is a frequent co morbidity in high risk neonates. Maternal diabetes, prematurity and Perinatal asphyxia ${ }^{1,4-7}$ are the important causes of early $\mathrm{NH}$. Late $\mathrm{NH}$ occurs after 1st week of life, usually symptomatic and requires long-term calcium therapy. ${ }^{4-6}$ Another entity, resistant or prolonged hypocalcemia is defined as symptomatic hypocalcemia not responding to appropriate doses of calcium supplementation, calcium requirement beyond $72 \mathrm{~h}$ of age in neonates orhypocalcemia manifesting beyond 1 st week of life. ${ }^{1}$ The index case in this report is of late onset variety.

Incidence of late onset hypocalcemia in breastfed neonates is $1 / 10000$ while, that in formula fed infants is $30 / 10000 .^{8}$ Late $\mathrm{NH}$ usually results from increased phosphate load (due to cow milk intake or renal insufficiency), hypomagnesemiaand hypoparathyroidism. ${ }^{1}$ Maternal vitamin $\mathrm{D}$ deficiency leading to neonatal vitamin $D$ deficiency is also reported to be a cause of late $\mathrm{NH} .{ }^{1}$ Vitamin $\mathrm{D}$ is an essential nutrient for bone health. Now it is well recognized that vitamin $D$ deficiency during intrauterine life and early childhood can lead to rickets, growth retardation, skeletal deformities and an increased risk of fracture. 9,10

As the index infant had hypocalcemia beyond first week of life, it qualifies for resistant or prolonged hypocalcemia due to vitamin $D$ deficiency. The index neonate had severe hypocalcemia (total $6 \mathrm{mg} / \mathrm{dL}$,) manifesting with seizures after first week of life and was investigated for neonatal seizures including the causes for late onset $\mathrm{NH}$ like hypomagnesemia, hypoparathyroidism and vitamin $\mathrm{D}$ deficiency. Evaluation for seizures revealed normal blood sugar levels, negative sepsis screen, sterile blood culture, ruling out hypoglycemia and septicaemia. Further evaluation for late onset $\mathrm{NH}$ showed normal serum magnesium and parathormone (PTH) levels, ruling out the possibility of hypomagnesemia and hypoparathyroidism. His serum $25 \mathrm{OH}$ vitamin D level was $19 \mathrm{ng} / \mathrm{mL}$ (<25 deficient, $75-250$ sufficient) confirming hypovitaminosis $\mathrm{D}$. As mother's vitamin $\mathrm{D}$ level was low, neonatal hypovitaminosis $D$ and symptomatic late onset neonatal hypocalcemia in this case can be attributed to the maternal vitamin $D$ deficiency.

Vitamin $D$ deficiency in neonatal period has been related to several environmental and maternal factors such as low ambient ultraviolet ray, limited sun exposure due to excessive sun avoidance, excessive clothing, host factor such as dark skin, obesity, aging, inappropriately low dietary intake, malabsorption syndrome, liver and renal disease and some medication (glucocorticoids, phenytoin, phenobarbital, rifampicin , highly active antiretroviral therapy). ${ }^{11-14}$

This case report emphasizes the need for the evaluation of neonatal and possibly maternal vitamin $D$ status in case of neonatal convulsion due to late onset hypocalcaemia.

To prevent such cases of late onset neonatal hypocalcaemia due to vitamin $D$ deficiency, oral vitamin D supplementation of pregnant women, lactating mothers and breastfed babies might be an effective public health measure. Also, the review and meta-analysis by Aghajafari et al. ${ }^{15}$ found associations between vitamin $D$ insufficiency and risk of gestational diabetes, pre-eclampsia, bacterial vaginosis and SGA infants. Hence Vitamin D supplementation may help both mother and baby. Daily vitamin D supplementation is safe in pregnancy. It can be given as cholecalceferol or ergocalciferol form.According to 2012 recommendation from UK Chief Medical Officers and NICE guideline, all pregnant and breastfeeding women should be informed about the importance of vitamin D and should take 10 micrograms (400 units) of vitamin D supplements daily. ${ }^{16,17}$ In case of high risk women extra care should be taken. Three categories of vitamin $\mathrm{D}$ supplementation are recommended for women:

1. In general, according to the UK national guideline all pregnant women is recommended to take vitamin D 10 micrograms (400 units) daily. ${ }^{18}$

2. High-risk women are advised to take at least 25 microgram or 1000 units daily. They are women 
with increased skin pigmentation, reduced exposure to sunlight, or those who are socially excluded or obese. ${ }^{19,20}$ The RCOG also highlighted the importance of giving suitable advice to these women. ${ }^{21}$ Women at high risk of preeclampsia are advised to take at least 20 microgram or 800 units $^{22}$ a day combined with calcium. ${ }^{23}$

3. Majority of women who are deficient in vitamin $\mathrm{D}$, are advised to take treatment for 4-6 weeks, either with cholecalciferol $20000 \mathrm{IU}$ a week or ergocalciferol $10000 \mathrm{IU}$ twice a week, followed by standard supplementation. ${ }^{24,25}$ The women who require short-term repletion, 20000 IU weekly appears to be an effective and safe treatment of vitamin $\mathrm{D}$ deficiency. A daily dose is likely to be appropriate to maintain subsequent repletion (1000 IU daily). A study in 2011 demonstrated that supplemental doses of 4000iu cholecalciferol a day were safe in pregnant women and most effective compared to the lower doses. ${ }^{26}$ Contrary to the recommendation, in the Lancet there is argument that routine supplementation of vitamin $D$ should be reserved for at-risk women rather than for all women. ${ }^{27}$ but this recommendation was on the basis of a large prospective cohort study showing no association between maternal serum vitamin $\mathrm{D}$ levels and bone mineral content in the children. ${ }^{28}$ However, although large, this was not randomized, did not consider supplementation and only looked at one indication.

Babies also need regular Vitamin D supplementation. Breast milk contains very little vitamin $D$, an average of 22 units/L (range 15 to 50 units/L) in a vitamin Dsufficient mother ${ }^{29}$ Though recent studies suggest that maternal intake of higher than recommended doses of vitamin D (4000 to 6400 units daily) can achieve its concentrations in breast milk which can be sufficient to provide adequate vitamin $D$ in breastfeeding infants, this approach is not recommended ${ }^{30}$. American Academy of Pediatrics now recommends minimum daily intake of 400 units vitamin $D$ per day in infants, children including adolescents to start soon after birth. The current recommendation replaces the previous recommendation of a minimum daily intake of $200 \mathrm{IU} /$ day of vitamin $D$ supplementation beginning in the first 2 months after birth and continuing through adolescence. ${ }^{31}$

\section{Conclusion}

In evaluation of hypocalcaemia in neonates, specially late onset variety, Vitamin $D$ status of the baby and the mother may help in clinical management. Preventive strategy should include maternal and infant vitamin D supplementation.

\section{References}

1. Jain A, Agarwal R, Sankar MJ, Deorari A, Paul VK. Hypocalcemia in the newborn. Indian J Pediatr. 2010;77:1123-28.

2. Singh J, Moghal N, Pearce SH, Cheetham T. The investigation of hypocalcaemia and rickets. Arch Dis Child. 2003;88:403-07.

3. Oden J, Bourgeois M. Neonatal endocrinology. Indian J Pediatr. 2000;67:217-23.

4. Schauberger CW, Pitkin RM. Maternal-perinatal calcium relationships. Obstet Gynecol. 1979;53:74-76.

5. Linarelli LG. Newborn urinary cyclic AMP and developmental responsiveness to parathyroid harmone. Pediatrics. 1972;50:14-23.

6. Hillman L, Rajanasathit S, Slatopolsky E, Haddad JG. Serial measurements of serum calcium, magnesium, parathyroid hormone, calcitonin, and 25-hydroxyvitaminD in premature andterm infants during the first week of life. Pediatr Res. 1977;11:739-44.

7. Schwartz R, Teramo KA. Effects of diabetic pregnancy on the fetus and newborn. Semin Perinatol. 2000;24:120-35.

8. Specker BL, Tsang RC, Ho ML, Landi TM, Gratton TL. Low serum calcium and high parathyroid hormone levels in neonates fed 'humanized' cow's milk-based formula. Am J Dis Child. 1991;145:941-45.

9. Centre for Disease Control and Prevention. Severe malnutrition among young children Georgia January 1997 - June 1999, JAMA. 285: 25733.

10. Kreiter SR, Schwartz RP, Kirkman HN Jr, Charlton PA, Calikoglu AS. Nutritional rickets in African American breast-feed infants. J Pediatr. 2000;137:153-57.

11. Bodnar LM, Simhan HN, Powers RW, Franks MP, Cooperstein E, Roberts. High Prevalence 
of vitamin $D$ insufficiency in black and white pregnant women residing in the northern United States and their neonates . J Nutri. 2007;137: 447-52.

12. Johnson DD, Wagner CL, Hulsey TC, McNei RB, Ebeling M, Hollis BW. Vitamin D deficiency and insufficiency National Institute for Health and Clinical Excellence. Antenatal care. NICE clinical guideline 62. Manchester: NICE. 2008.

13. Hamilton SA, McNeil R, Hollis BW, Davis DJ, Winkler J, Cook C et al. Profound vitamin D deficiency in a diverse group of women during pregnancy living in a sun rich environment at latitude $32 \mathrm{~N}$. Int J Endocrinol. 2010.

14. Ginde AA, Sullivan AF, Mansbach JM, Camargo $C A$, Jr. Vitamin $D$ insufficiency in pregnant and nonpregnant women of child bearing age in the United States. Am J of Obstet Gynecol. 2010;202:436.el-436.e8.

15. Aghajafari F, Nagulesapillai T, Ronksley PE, Tough SC, O'Beirne M, Rabi DM. Association between maternal serum 25-hydroxyvitamin D level and pregnancy and neonatal outcomes: systematic review and meta-analysis of observational studies. BMJ. 2013; 346: f1169

16. Chief Medical Officers for the United Kingdom. Vitamin D - advice on supplements for at risk groups. Cardiff, Belfast, Edinburgh, London: Welsh Government, Department of Health, Social Services and Public Safety, The Scottish Government, Department of Health; 2012 [http://www.scotland.gov.uk/Resource/ 0038/00386921.pdf].

17. National Institute for Health and Clinical Excellence. Antenatal care. NICE clinical guideline 62. Manchester: NICE; 2008

18. Chief Medical Officers for the United Kingdom. Vitamin D - advice on supplements for at risk groups. Cardiff, Belfast, Edinburgh, London: Welsh Government, Department of Health, Social Services and Public Safety, The Scottish Government, Department of Health; 2012 [http://www.scotland.gov.uk/Resource/ 0038/00386921.pdf].

19. Hollis BW. Vitamin $D$ requirement during pregnancy and lactation. J Bone Miner Res. 2007;22Suppl 2:V39-44.
20. Dawson-Hughes B, Heaney RP, Holick MF, Lips P, Meunier PJ, Vieth R. Estimates of optimal vitamin D status. OsteoporosInt. 2005;16:713-16.

21. RCOG Statement on vitamin D supplementation for pregnant women [http://www. rcog.org.uk/ what-we-do/campaigning-and-opinions/ statement/rcog-statementvitamin-d-supplementation-pregnant-wome].

22. Haugen $M$, Brantsaeter $A L$, Trogstad $L$, Alexander J, Roth C, Magnus P, et al. Vitamin D supplementation and reduced risk of preeclampsia in nulliparous women. Epidemiology 2009;20:720-26.

23. Ito $\mathrm{M}$, Koyama $\mathrm{H}$, Ohshige $\mathrm{A}$, Maeda $\mathrm{T}$, Yoshimura T, Okamura H. Prevention of preeclampsia with calcium supplementation and vitamin D3 in an antenatal protocol. Int J Gynaecol Obstet. 1994;47:115-20.

24. Saadi HF, Dawodu A, Afandi BO, Zayed R, Benedict S, Nagelkerke N. Efficacy of daily and monthly high-dose calciferol in vitamin D-deficient nulliparous and lactating women. Am J Clin Nutr. 2007;85:1565-71.

25. Kennel KA, Drake MT, Hurley DL. Vitamin D deficiency in adults: when to test and how to treat. Mayo Clin Proc. 2010;85:752-57.

26. Hollis BW, Johnson D, Hulsey TC, Ebeling M, Wagner CL. Vitamin D supplementation during pregnancy: double-blind, randomized clinical trial of safety and effectiveness. J Bone Miner Res. 2011;26:2341-57.

27. Steer PJ. Is vitamin $D$ supplementation in pregnancy advisable? Lancet. 2013;381:2143-45.

28. Lawlor DA, Wills AK, Fraser A, Sayers A, Fraser WD, Tobias JH. Association of maternal vitamin D status during pregnancy with bone-mineral content in offspring: a prospective cohort study. Lancet. 2013;381:2176-83.

29. Leerbeck $E$, Sondergaard $H$. The total content of vitamin $\mathrm{D}$ in human milk and cow's milk. $\mathrm{Br} \mathrm{J}$ Nutr. 1980;44:7-12.

30. Basile LA, Taylor SN, Wagner CL. The effect of high-dose vitamin $D$ supplementation on serum vitamin $D$ levels and milk calcium concentration in lactating women and their infants. Breastfeed Med. 2006;1:27-35.

31. Wagner CL, Greer FR. Prevention of rickets and vitamin $D$ deficiency in infants, children, and adolescents. Pediatrics. 2008;122:1142-52. 